NASA Technical Memorandum 89921

AIAA-87-1764

\title{
Thermodynamic Analysis and Subscale Modeling of Space-Based Orbit Transfer Vehicle Cryogenic Propellant Resupply
}

David M. DeFelice and John C. Aydelott

Lewis Research Center

Cleveland, Ohio

(KASA-TH-89921) TBERECLYAHIC AHALISIS AU

SCBSCALE HODELIVG OF SFACE-EIELD ORETT

TFAUSFER VEAICLE CRYCGEMIC EECFELLAUT

EESUEELY (BASA) 21 F Avail: MIIS HC

$A C Z / \triangle F \quad O 01$

CSCL 20D G3/34 Unclas

Prepared for the

23rd Joint Propulsion Conference

cosponsored by the AIAA, SAE, ASME, and ASEE

San Diego, California, June 29-July 2, 1987 
THERMODYNAMIC ANALYSIS AND SUBSCALE MODELING OF SPACE-BASED ORBIT TRANSFER

\title{
VEHICLE CRYOGENIC PROPELLANT RESUPPLY
}

\author{
David M. DeFelice and John C. Aydelott \\ National Aeronautics and Space Administration \\ Lewis Research Center \\ Cleveland, onio 44135
}

\section{SUMMARY}

The resupply of the cryogenic propellants is an enabling technology for space-based orbit transfer vehicles. As part of NASA Lewis's ongoing efforts in microgravity fluid management, thermodynamic analyses and subscale modeling techniques have been developed to support an on-orbit test bed for cryogenic fluid management technologies. Analytical results have shown that subscale experimental modeling of liquid resupply can be used to validate analytical models when the appropriate "target" temperature is selected to relate the model to its prototype system. Further analyses have been used to develop a thermodynamic model of the tank chilldown process which is required prior to the no-vent fill operation. These efforts have been incorporated into two FORTRAN programs which have been used to present preliminary analytical results.

\section{INTRODUCTION}

A number of future NASA and DOD missions have been identified that will require, or could benefit from, the resupply of cryogenic liquids on orbit. Prominent among these fluids are the cryogenic propeliants required for the next generation of reusable, space-based vehicles such as the Orbit Transfer Vehicle (OTV). The enabling technologies required for these vehicles include those associated with the transfer of cryogens from storage systems into the vehicle tankage. Mission success is dependent upon accurate filling techniques and efficient filling is critical due to the high costs associated with providing propellants on orbit. Spacecraft designers and mission planners must have confidence in the analytical models and design criteria being established by on-orbit, subscale experimentation.

AS NASA's lead center for microgravity fluid management and propulsion technologies, NASA Lewis is developing the Cryogenic Fluid Management Fight Experiment (CFMFE). The CFMFE is an on-orbit test bed that will demonstrate cryogenic fluid management technologies and verify the analytical models being developed as the "end 1tems" of our efforts. Spacecraft and financial limitations dictate that the tankage be of reduced scale relative to prototype storage and transfer systems. Straight-forward thermodynamic analyses provide proof that subscale modeling can be effective and rellable for the development of detalled analytical models of the cryogenic resupply of 0TVs, as well as other prototypical space systems.

Due to the reduction of gravity in the space environment, the on-orbit filling of cryogenic tankage is radically different from ground-based operations. The "thermodynamic" fllling technique, as developed and presented in references 1 and 2 , has been selected to provide an efficient solution to this 
low-gravity fluid management problem. The approach utilizes an initial chilldown of the tank (including vapor-only venting) followed by a no-vent fill. The key to the successful filling of the tank and the efficient usage of the avallable propellant is the selection of an appropriate tank pressure after completion of the filling operation. The desired tank pressure will be successfully controlled if the tank temperature prior to initiating the fill process is properly selected. This required pref 111 tank temperature is referred to as the "target" temperature of the chilldown process for the specific tank. A thermodynamic analysis of the no-vent f 111 process can be conducted using the hardware characteristics and the desired fluid conditions subsequent to the tank filling. The analysis yields a logical prediction of the required "target" temperature, and moreover, can directly relate a subscale system to its prototype. Further thermodynamic analyses incorporating selected condensation heat transfer coefficlents and system requirements can enable the selection of cryogen mass flow rates and liquid injection techniques for the CFMFE.

As previously mentioned, the first process in the "thermodynamic" filling technique is tank chilldown. The approach utilizes the cyclic "charge-holdvent" method to remove the thermal energy stored in the tank wall in stages. This approach to on-orbit filling of cryogenic tankage maximizes the cooling potential of the injected liquid cryogen by allowing the resultant vapor to superheat to near the tank wall temperature. This method, however, can be significantly improved by cyclically venting the vapor in stages, making available an even greater heat-sink capacity. A thermodynamic model reveals that a potential 23 percent savings in the propellant required for the chilldown of a tank can be achieved by cyclic venting.

As a part of these efforts, two FORTRAN codes were developed: one to select scaled "target" temperatures and the other to enable a quick but accurate prediction of the cryogen requirements for tank chilldown. They also serve as useful tools for the parametric evaluation of such key characteristics of the tank hardware as the size, mass-to-volume ratio, maximum operating pressure, and with additional subroutines, tank material as well. This paper documents both the no-vent fill and chilldown analyses developed to support the CFMFE design effort and presents some of the preliminary analytical results.

\section{BACKGROUND}

For approximately 25 years, the goal of the NASA Lewis efforts in reducedgravity fluid management research and development has been the generation of technology that will enable the design of efficlent systems for managing fluids in the space environment (ref. 3). The general approach in this effort is to develop and verify analytical modeling and scaling techniques by experimentation. Having developed the basic understanding of low-g fluid behavior, NASA Lewis has been defining specific mission/vehicle technology needs with an emphasis on cryogenic fluid management systems. To support this effort, we sponsored several contracted studies (refs. 4 to 7 ) which identified the gaps in cryogenic fluid management technologies and defined on-orbit experimental concepts. The need to develop enabling technologies for future NASA and DOD missions, as we 11 as the limitations of ground-based test faclilities, have resulted in the definition of an on-orbit test bed, the CFMFE, which wili verify the analytical models and demonstrate these technologies. The CFMFE is the primary focus of the efforts within the Cryogenic Fluid Management Project office (CFMPO) at NASA 
Lewis. It is part of an overall program which also includes ground-based supporting technology experimentation.

The low-g cryogentc fluid management technologies are grouped into the three primary categories of fluid storage, supply and transfer with the additional technologies associated with fluid handling and advanced instrumentation. The storage technologies are concerned with the performance of thermal protection and pressure control systems. The supply technologies are concerned with acquiring single-phase liquid and conditioning it for subsequent transfer operations, and include the performance of Liquid Acquisition Devices (LADS), Iiquid settiing techniques, and pressurization systems. The transfer technologies, on which this paper focuses, are concerned with transporting the single-phase liquid from a storage and supply system to a user fluid system. The fluid handing technologies are concerned with fluid management issues such as slosh dynamics, while advanced instrumentation includes devices for quantity gaging and leak detection. The NASA Lewis cryogenic fluid management program will design and develop these technologies into an integrated fluid management system.

Liquid hydrogen has been selected as the CFMFE experimental fluid because of its prominent planned use for future NASA and DOD missions. In addition, liquid hydrogen was selected because it presents challenging in-space fluid management requirements due to its low temperature, density, and surface tension properties. Obtaining low-g cryogenic liquid storage, acquisition and transfer data with hydrogen should lead to the development of design criteria generally applicable to other cryogenic fluids, with the exception of liquid helium. For this reason, all of the analyses herein will be performed with liquid hydrogen. The analytical and numerical models developed, however, are valid for any cryogenic fluid.

\section{THERMODYNAMIC ANALYSES}

\section{No-Vent F111 Description}

The initial conditions of the receiver tank for a no-vent fill are totaliy evacuated, all vents closed, and the walls at a specified "target" temperature, that is the final chilldown temperature. This "target" temperature will be somewhat above the temperature of the incoming propellant, because as the following analysis will show, a total tank chilldown is unnecessary so long as there is some subcooling of the injected fluid and the final fill level is less than 100 percent. Examination of the thermodynamics of the receiver tank during a no-vent fill liquid transfer process can be considered in three phases. The first phase, starting at the beginning of the transfer, involves vaporization of the incoming liquid. Part of the incoming liquid will vaporize rapidiy, or flash, at the nozzle exit. This will continue as long as the pressure in the tank is lower than the vapor pressure of the incoming liquid. Because there will be some residual thermal energy in the tank hardware, any liquid that does not flash will vaporize due to heat transfer with the wall and the accumulating vapor. This will continue until all of the thermal energy has been removed from the wall.

At this point, liquid begins to accumulate in the tank, marking the beginning of the second phase. Continued inflow causes compression of the vapor, and the tank pressure will continue to rise. Once the tank pressure reaches the vapor pressure of the accumulated liquid at the liquid-vapor interface, 
vapor will begin to condense; this is the third phase of the process. When the receiver tank pressure reaches its specified maximum operating limit, further transfer into the tank can occur only as condensation of the vapor makes room for more liquid.

Condensation of vapor is the most important process in the no-vent f 111 procedure. The tank wall and liquid-vapor interfaclal area avallable for condensation, as well as the rate at which condensation occurs, will limit the rate at which the transfer can proceed. During the highly transient no-vent fill operation, whenever the liquid interface is at a temperature that is below the saturation temperature corresponding to the tank pressure, vapor will condense at the interface. However, this condensation deposits the heat of condensation into the interface layer, and quickly raises its temperature to the saturation point. Further condensation is dependent on transfer of heat from the interface into the bulk of the liquid. Consequently, to enhance this heat transfer, means for promoting mixing should be considered.

Under reduced-gravity conditions, the liquid-vapor interface configuration is established primarily by surface tension forces. However, the interface position and area will also be influenced by the flow of liquid into the tank. The interface area is expected to increase due to mixing induced generation of vapor bubbles within the liquid. The bubbles may not completely separate from the liquid or coalesce due to the lack of buoyancy in the reduced-gravity environment. Consequently, determining the effectiveness of mixing methods and the resulting prediction of condensation rates is expected to be more difficult than would be anticipated for earth based experiments.

As the quantity of liquid transferred increases, the volume of the vapor decreases, and as the tank approaches a nearly full condition, the total interfaclal area, regardless of the mixing mode, decreases. Therefore, it is possible that the rate of liquid transfer will be severely reduced as the tank approaches a nearly filled condition.

\section{Analysis of Subscale Tankage}

Target temperature prediction. - Figure 1 is a schematic drawing of a receiver tank which is initially evacuated. The thermodynamic analys is is initiated by formulating the equations for conservation of mass and energy.

Assume an initially evaluated tank.

Mass balance: $m_{L, I}=m_{L, f}+m_{v, f}$

Energy balance: $h_{L, I} m_{L, I}+q+m_{t} \int_{T_{f}}^{T} c p_{t} d T=u_{L, f} m_{L, f}+u_{v, f} m_{v, f}$

Define: $\quad \Delta E=q+m_{t} \int_{T_{f}}^{T} c p_{t} d T=u_{L, f} m_{L, f}+u_{v, f^{m}} m_{, f}-h_{L, I} m_{L, I}$

As first approximation assume: $q=0$ and $m_{v, f}=0$ 
(i.e., the heat addition to the receiver tank during the filling process and the final energy content of the vapor are negligible. This is generally true for high fill levels. However, the vapor terms have been retained in the computer model for all cases.)

We can also approximate: $u_{L, f}-h_{L, I}=C p_{L} \Delta T_{L}$ and $m_{L, f}=m_{L, I}=\rho_{L} V_{t}$

This yields: $\Delta E=C p_{L} \Delta T_{L} \rho_{L} V_{t}=m_{t} \int_{T_{f}}^{T} C p_{t} d T$

Thermodynamic similarity is based on thermal equilibrium when, in fact, finite energy transport occurs. Liquid vapor interfactal heat and mass transfer (condensation) is assumed to be the controlling energy transport phenomenon during the tank filling process. This assumption is based on a fill procedure where the initial entering liquid vaporizes to complete tank cooling and then the energy transfer to the remaining entering liquid occurs by way of the vapor condensation process.

For the condensation process, the change in energy is:

$$
\Delta E=\dot{q}_{C} A \Delta t
$$

where

$$
\dot{q}_{c}=h_{c} \Delta T_{L} \propto \rho_{L} C p_{L} v\left[\frac{\mu_{L}}{\rho_{L}^{2}}\left(\frac{\dot{m}_{L}}{v^{2} v_{t}}\right)\right]^{n}\left(\frac{C p_{L} \mu_{L}}{k_{L}}\right)^{m} \cdot \Delta T_{L}
$$

Based on available data, our experimental configuration should produce experimental results consistent with: $n=1 / 4$ and $m=-1 / 2$ (ref. 8 ).

Substituting for $n$ and $m$ and rearranging yields:

$\dot{q}_{c}=h_{c} \Delta T_{L} \propto \frac{\rho_{L}^{1 / 2} C_{p_{L}}^{1 / 2} k_{L}^{1 / 2}}{\mu_{L}{ }^{1 / 4}} \cdot\left(\frac{\dot{m}_{L}{ }^{2}}{v_{t}}\right)^{1 / 4} \cdot \Delta T_{L}=F\left(\frac{\dot{m}_{L}{ }^{2}}{v_{t}}\right)^{1 / 4} \cdot \Delta T_{L}$

where $F$ is only a function of flutd properties.

So we can provide thermodynamic similarity if:

$$
\left(\Delta T_{L}\right)_{m}=\left(\Delta T_{L}\right)_{p}
$$

and equality of key energy transport phenomenon if :

$$
\left(\dot{q}_{c}\right)_{m}=\left(\dot{q}_{c}\right)_{p} \text { or }\left(\frac{\dot{m}_{L} v_{L}^{2}}{v_{t}}\right)_{m}^{1 / 4}=\left(\frac{\dot{m}_{L} v_{L}^{2}}{v_{t}}\right)_{p}^{1 / 4}
$$


Substituting the left side of equation (5) into equation (9) yields:

$$
\left(\frac{\Delta E}{C p_{L} \rho_{L} V_{t}}\right)_{m}=\left(\frac{\Delta E}{C p_{L} \rho_{L} v_{t}}\right)_{p}
$$

Recombining with the right side of equation (5) yields:

$$
\begin{aligned}
& \Delta E_{m}=\left(m_{t} \int_{T_{f}}^{T} c p_{t} d T_{t}\right)_{m}=\frac{\left(C p_{L} \rho_{L} V_{t}\right)_{m}}{\left(C p_{L} p_{L} V_{t}\right)_{p}}\left(m_{t} \int_{T_{f}}^{T_{1}} c p_{t} d T_{t}\right)_{p} \\
& \left(\int_{T_{f}}^{T} c p_{t} d T_{t}\right)_{m}=\frac{\left(C p_{L} \rho_{L} v_{t}\right)_{m}}{\left(C p_{L} \rho_{L} V_{t}\right)_{p}} \cdot \frac{\left(m_{t}\right)_{p}}{\left(m_{t}\right)_{m}}\left(\int_{T_{f}}^{T} c p_{t} d T_{t}\right)_{p}
\end{aligned}
$$

Using liquid hydrogen as the test fluid and the same materials for both tanks:

$$
\left(C p_{L}\right)_{m}=\left(C p_{L}\right)_{p} \quad\left(\rho_{L}\right)_{m}=\left(p_{L}\right)_{p} \quad\left(C p_{t}\right)_{p}=\left(C p_{t}\right)_{m}=f\left(T_{t}\right)
$$

and if we maintain the same final pressure in both tanks, then

$$
\left(T_{f}\right)_{m}=\left(T_{f}\right)_{p}
$$

Therefore, equation (13) leads to the desire for:

$$
\left(\frac{m_{t}}{v_{t}}\right)_{m}=\left(\frac{m_{t}}{v_{t}}\right)_{p}
$$

If equal mass/volume ratios could be maintained:

$$
\left(T_{1}\right)_{m}=\left(T_{1}\right)_{p}
$$

However, subscale modeling is required due to envelope, mass, and cost constraints. Since prototypical space-based OTVs are designed with walls of minimum gage, and experiment designs dictate higher operating pressures and factors of safety, equal mass-to-volume ratios are unattainable. Even if the tank wall thicknesses could be matched, the mass-to-volume ratio would be different because the volume of a tank will vary as the cube of the tank radius while the mass will vary as the square of the tank radius. Thus, as the tank size is reduced, you would require thinner walls to maintain the mass-to-volume ratio between the model and prototype tanks, and such fabrication is impossible.

Therefore:

$$
\left(\frac{m_{t}}{v_{t}}\right)_{m}>\left(\frac{m_{t}}{v_{t}}\right)_{p}
$$


so we must select: $\left(T_{f}\right)_{m}<\left(T_{f}\right)_{p}$ to maintain thermodynamic modeling. These temperatures are the "target" temperatures which must be attained by the tank chilldown process.

To enable the logical selection of this "target" temperature, the above analysis was incorporated into a FORTRAN code named TARGET. The code is operated by varying the initial tank temperature and calculating the required saturation conditions in the source tank. A minimum value of 2 psia was assumed for the saturation conditions attainable for an orbiting source tank. The results can be presented in graphical form by plotting the pressure difference between the saturation conditions in the source and receiver tanks, 1.e., the required liquid subcooling. To demonstrate this, we can compare a Boeing concept for a space-based OTV* to a 0.25 scaled model of the same tank.

Table 1 (a) describes the two tanks and table 1 (b) lists the operating conditions. The 20 psia final condition is typical for the maximum operating pressures of space-based OTVs and f 111 levels of 95 percent or better may be required for mission success. The results are presented in figure 2 and summarized in table $1(c)$.

If we assume an orbiting cryogenic depot operating at one atmosphere to be our source tank, we can select $\Delta \mathrm{P}=5 \mathrm{ps}$ i as the design condition. The required "target" temperature for the OTV will be $393^{\circ} R(218 \mathrm{~K})$ and the model "target" temperature required to maintain the integrity of the modeling should be $157^{\circ} R(87 \mathrm{~K})$. Note from this analysis that a "target" temperature implies an avallable subcooling and a final tank percent-filling which will be the same for the model and prototype tankage. Thus we have a logical approach towards the required subscale modeling. This approach can be confirmed by on-orbit transfer operations with two subscaled tanks with different scale factors by relating them to each other in this way.

Figure 2 also provides other insights into the thermodynamics of the nonvented filling of subscaled tankage. Note that the curve for the model tank is truncated at a pressure difference of $18 \mathrm{psi}$. This shows that if the initial tank temperature was above $350^{\circ} R(194 \mathrm{~K})$ that a nonvented $\mathrm{f} 111$ to or above 95 percent full would be impossible for this specifled tank and set of conditions. The other significant point of interest is that the lines for the model and prototype tanks converge near the injected liquid saturation temperature, the case for the no-vent fill of "cold" tanks. The fact that this occurs at a pressure difference above zero indicates the necessity for some liquid subcooling due to the work of compression during the fill process.

In a simflar manner we can develop requirements for the mass flow rate and time scaling of subscale tankage.

Receiver tank filling time. - Substituting equation (6) into the left side of equation (10), then combining with equation (5) yields:

$$
\left(\frac{\Delta E}{A \Delta t}\right)_{m}=\left(\frac{\Delta E}{A \Delta t}\right)_{p}
$$

*Information submitted for publication by Boeing Aerospace Co., Seattle, WA to NASA George C. Marshall Space Flight Center under Contract NAS8-36107: Orbital Transfer Vehicle Concept Definttion and System Analysis Study. Final Report, vol. 1 (rev. A), Executive Summary, 0180-29108-1, 1986. 


$$
\left(\frac{C p_{L} \Delta T_{L} p_{L} V_{t}}{A \Delta t}\right)_{m}=\left(\frac{C p_{L} \Delta T_{L} p_{L} V_{t}}{A \Delta t}\right)_{p}
$$

Noting that we can maintain $\left(\Delta T_{L}\right)_{m}=\left(\Delta T_{L}\right)_{p}$ and rearranging utilizing a linear scale factor yields:

$$
\begin{gathered}
\frac{(\Delta t)_{m}}{(\Delta t)_{p}}=\frac{(A)_{p}}{(A)_{m}} \cdot \frac{\left(V_{t} \rho_{L} C p_{L}\right)_{m}}{\left(V_{t} \rho_{L} C p_{L}\right)_{p}}=\frac{s^{3}}{s^{2}} \cdot \frac{\left(\rho_{L} C p_{L}\right)_{m}}{\left(p_{L} C p_{L}\right)_{p}} \\
\frac{(\Delta t)_{m}}{(\Delta t)_{p}}=\frac{\left(\rho_{L} C p_{L}\right)_{m}}{\left(\rho_{L} C p_{L}\right)_{p}} \cdot s
\end{gathered}
$$

Using $\mathrm{LH}_{2}$ as the experimental fluld:

$$
(\Delta t)_{m}=S(\Delta t)_{p}
$$

Thus, it would take a quarter of the time to fill a 0.25 scaled model tank compared to its prototype.

Liquid transfer rate. - The average liquid inflow rate is determined from a mass balance:

$$
\dot{m}_{L, I} \Delta t=\rho_{L} V_{t} \cdot f
$$

For the same fill levels:

$$
\frac{\left(\dot{m}_{L, I}\right)_{m}}{\left(\dot{m}_{L, I}\right)_{p}}=\frac{\left(\rho_{L} V_{t}\right)_{m}}{\left(\rho_{L} V_{t}\right)_{p}} \cdot \frac{(\Delta t)_{p}}{(\Delta t)_{m}}
$$

Combining with equation (19b) yields:

$$
\frac{\left(\dot{m}_{L, I}\right)_{m}}{\left(\dot{m}_{L, I}\right)_{p}}=\frac{\left(V_{t}\right)_{m}}{\left(V_{t}\right)_{p}} \cdot \frac{1}{s} \cdot \frac{\left(C p_{L}\right)_{p}}{\left(C p_{L}\right)_{m}}=\frac{s^{3}}{s} \cdot \frac{\left(C p_{L}\right)_{p}}{\left(C p_{L}\right)_{m}}=\frac{\left(C p_{L}\right)_{p}}{\left(C p_{L}\right)_{m}} s^{2}
$$

For $\mathrm{LH}_{2}$ testing:

$$
\frac{\left(\dot{m}_{L, I}\right)_{m}}{\left(\dot{m}_{L, I}\right)_{p}}=s^{2} \text { or }\left(\dot{m}_{L, I}\right)_{m}=\left(\dot{m}_{L, I}\right)_{p} \cdot s^{2}
$$

Thus, the liquid transfer rate into a 0.25 scaled model tank would be 6.25 percent of the prototype inflow rate. Similar analyses can be used to select liquid spray nozzle sizes and other hardware characteristics to maintain the proper scaling. 
Having developed the theory enabling the prediction of "target" temperatures, we can proceed with the discussion of the receiver tank chllldown process. Unless the receiver tank has some residual liquid (in which case we would refer to the transfer operation as a "no-vent refili"), the tank will be relatively warm and thus require a tank chllidown operation prior to filling. In addition to being unnecessary (see section describing the no-vent fill). it would be inefficient to chill the tank all the way to the final propellant temperature due to the thermal properties of typical tank materials, such as aluminum. Chilling the tank to the saturation temperature of the incoming propellant could cause premature liquid accumulation, and liquid would be vented during the vent preceding the no-vent fill. The purpose of the chilldown, then, is to remove enough of the thermal energy stored in the walls and any internal or external hardware (e.g. LADS, support struts, and insulation systems) to allow the tank temperature to be reduced to its "target" temperature.

Receiver tank chilldown must be accomplished in a timely and efficlent manner in a microgravity environment. The efficient use of propellants requires that no liquid be vented overboard and that the cooling capacity of the cryogen be fully utilized. The primary operational concern during receiver tank chilldown is insuring that the tank is not overpressurized by the vaporization of the injected liquid. This concern increases as the tank scale is reduced and the mass-to-volume ratio increases.

The "charge-hold-vent" chilldown method meets the requirements stated. With the tank vents closed, a small amount of liquid is injected into the tank through spray nozzles which impart a persisting fluid velocity. The liquid vaporizes in part due to flashing, and eventually, in total due to heat transfer with its own vapor, which rapidly heats up due to heat absorption from the tank walls. Following the liquid inflow, the resultant vapor is held in the tank to allow adequate time for heat removal from the tank wall and hardware. Venting will begin when significant heat transfer ceases. Venting in stages allows further heat transfer to occur because of the cooling of the remaining vapor due to its isentropic expansion. Venting proceeds until the tank is once again evacuated, and then a new chilldown cycle begins with the next liquid charge.

\section{Tank Chilldown Analys is}

Referring once again to figure 1 , for an initially evacuated tank we can formulate the equations for conservation of mass and energy during the charge and hold portions of any one chllidown cycle.

Mass balance: $m_{L, I}=m_{V, f}=m_{I}$

since all of the injected liquid will be vaporized. 
Energy balance: $h_{L, I} m_{I}+q+m_{t} \int_{T_{f}}^{T} c p_{t} d T=u_{v, f} m_{I}$

Where $T_{j}$ is the tank temperature prior to the liquid injection and $T_{f}$ is the tank temperature prior to the initiation of venting.

As a first approximation we will assume: $q=0$

If the chilldown cycles are done over small temperature ranges, we can approximate the tank energy term as:

$$
m_{t} \bar{c} p_{t}\left(T_{1}-T_{f}\right)
$$

where $\bar{C}_{t}$ represents an average value.

Rearranging and solving for the final tank temperature yields:

$$
T_{f}=T_{i}-\frac{m_{I}\left(u_{v, f}-h_{L, I}\right)}{m_{t} \bar{C}_{t}}
$$

To insure that the tank is not overpressurized, the allowable liquid charge for each chllidown cycle must be calculated. Since the vapor will always end up well above its saturation temperature, we can apply the ideal gas law without corrections:

$$
m_{I}=\frac{P_{f} V_{f}^{M}}{R_{u} T_{v, f}}
$$

Since, in practice, it would be impractical to wait for the steady-state final condition in which the wall and vapor are in thermal equilibrium, we will assume that the vapor only warms up to 95 percent of the wall temperature.

Substitution into equation (29) yields:

$$
T_{f}=T_{f}-\frac{\left(u_{v, f}-h_{L, I}\right)}{\tau_{p_{t}} T_{f}} \cdot 0
$$

where $D=\frac{P_{t} V_{t} M}{0.95 m_{t} R_{u}}$ is a constant for all chilldown cycles.

A final rearrangement yields a quadratic equation for $T_{f}$ :

$$
T_{f}^{2}-T_{f} T_{f}+\frac{\left(u_{v, f}-h_{L, I}\right)}{C p_{t}} \cdot 0=0
$$


However, since both $u_{v, f}$ and $\bar{c} p_{t}$ are defined at the end state, the solution procedure must be iterative.

Each vapor vent cycle can be modeled by two processes which are repeated until the tank is evacuated and ready for the next chilldown cycle to begin. The first process, vapor venting, can be approximated as an adiabatic, reversible expansion of the remaining vapor to the lower pressure. Thus, decreasing the pressure isentropically enables the evaluation of the fluid properties at a well defined intermediate state. The vapor temperature at this state, as well as a new value of the vapor mass, can now be determined.

Applying a new energy balance between this cooled vapor mass and the tank wall yields:

$$
T_{2}=T_{1}-\frac{\left(u_{v, 2}-u_{v, 1}\right)}{m_{t} \bar{c} p_{t}} \cdot m_{v}
$$

where $u_{v, 2}$ is evaluated at a temperature 95 percent of $T_{2}$. (For the first vent cycle $T_{1}=T_{f}$ ) Again the solution procedure must be iterative. After convergence, the wall temperature is reset $\left(T_{1}=T_{2}\right)$ and more vapor is vented. At the end of all the venting cycles the tank will have been evacuated again, and we can reset $T_{1}=T_{2}$ and begin a new chilldown cycle with the next

liquid charge.

Table 2 is an example of a typical output for the FORTRAN chilldown code CRYOCHIL. The test case is for the 0.25 scaled model OTV tank as described in table 1 (a) with the conditions listed in table $l(b)$. The tank was chilled from an initial temperature of $530^{\circ} \mathrm{R}(294 \mathrm{~K})$ to the previously determined target temperature of $157^{\circ} R(87 \mathrm{~K})$. These results and the results for the prototype OTV are summarized in table $7(c)$. The fact that the liquid mass required for the chilldown of the prototype OTV tank is only 0.20 percent of the tank volume indfcates that the penalty for an errant prediction is not very great, leaving a comfortable margin for error. The 5.52 percent value for the model tank indicates that a predictive capability is more critical for subscale operations and could significantly affect the on-orbit life of an experiment incorporating multiple tank chilldowns. This type of information is useful for predicting the number of chilldown cycles and the propellant mass required. For the CFMFE, this code could be used for mission planning, operational scenario development, and fluid mass inventory. By parametrically varying such parameters as the tank mass, volume and operating pressure, engineering trade studies can be accomplished.

To demonstrate the potential value of this code, a simple parametric analysis was done on a receiver tank chilldown operation. Figure 3 shows the effect of varying the number of the vent cycles on the tank wall temperature for the quarter-scale model of the SB-OTV. Decreasing the magnitude of the tank pressure drop during each vent cycle, 1.e., increasing the number of vent cycles, increases in the heat-sink capacity of the remaining fluid after venting. Decreasing the pressure drop for each vent cycle from 60 to 1 psi would provide an additional 32 percent decrease in the tank wall temperature drop. Even the more practical 10 psi pressure drop per vent cycle provides a 22 percent increase in temperature drop. Over a complete receiver tank chilldown, figure 4 shows that a 23 percent fluid mass savings can be obtained (for the specified tank and conditions) by decreasing vent cycle pressure drops to 
1 psi each. Note that the actual number of vent cycles tends to be larger than the exact multiple due to a pressure recovery caused by the heat transfer to the vapor from the tank wall between the vent cycles. This type of parametric study shows the benefit of developing additional operational control algorithms for the chllldown portion of the fluid transfer process. The actual trade studies, however, must take an anticipated heat flux into account.

\section{CONCLUDING REMARKS}

The thermodynamic models and the scaling techniques which have been presented are currently being used by the CFMPO at NASA Lewis. The thermodynamically based code, TARGET, is sufficient in its present form to preform quantitative analyses. So long as the assumption that there is sufficient fluid mixing to promote condensation heat transfer is true, consideration of transient phenomena is not necessary for the selection of the tank "target" temperature. A separate effort to model the dynamics of the no-vent f 111 process is underway.

The CRYOCHIL code, as described, is sufficlent for performing fluid inventory analyses and parametric investigations. However, work is in progress to include within it models of all the transient phenomena which will effect the tank chilldown process. This will enable the prediction of pressure and temperature histories, as well as tank temperature profiles. The information gathered in the ground-based supporting technology experimental program will provide preliminary verification of these models prior to fight experimentation. 


\section{APPENDIX A - Symbols}

A liquid-vapor interface area

Cp specific heat at constant pressure

E energy

F fluid properties function

f percent filling

h specific enthalpy

$h_{c}$ condensation heat transfer coefficient

$k$ thermal conductivity

M molecular mass

m mass

$\dot{m}$ mass flow rate

P pressure

q heat transferred

$q_{c}$ condensation heat transfer rate

$R_{u} \quad$ universal gas constant

S linear scale factor

$\mathrm{T}$ temperature

$t$ time

u specific internal energy

v volume

Greek:

$\Delta \quad$ final conditions - initial conditions (unless otherwise defined)

$\mu \quad$ viscosity

v injection veloctty

p density 


\section{Subscripts:}

f final conditions

I inlet conditions

1 inftial conditions

L liquid

m model

p prototype

t tank

$\checkmark \quad$ vapor

1 conditions after current vent

2 conditions prior to the next vent

Other Symbols

$\Delta T_{L}$ The surface to bulk temperature difference, assumed to be a linear function of the difference between the saturated liquid temperature at the receiver tank pressure and the inflowing liquid temperature. 


\section{ORIGINAL FACE PS \\ OE POOR QUALITY}

\section{REFERENCES}

1. Merino, F., Blatt, M.H., and Thies, N.C., "Filling of Orbital Fluid Management Systems," CASD-NAS-78-010, General Dynamics/Convair, San Diego, CA, July 1978. (NASA CR-159404).

2. Merino, F., Risberg, J.A., and Hill, M., "Orbital Refill of Propulsion Vehicle Tankage," GDC-CRAD-80-001, General Dynamics/Convair, San Diego, CA, Feb. 1980. (NASA CR-159722).

3. Aydelott, J.C., Carney, M.J., and Hochstein, J.I., "NASA Lewis Research Center Low-Gravity Fluid Management Technology Program," AIAA/GNOS Paper 85-002, Nov. 1985. (A1so, NASA TM-87145).

4. Stark, J.A., "Low-G Fluid Transfer Technology Study," CASD-NAS-76-014, General Dynamics/Convair, San Diego, CA, May 1976. (NASA CR-134911).

5. Stark 3. A., "Low-G Fluid Transfer Technology Study, Executive Summary," CASD-NAS-76-017, General Dynamics/Convair, San Diego, CA, May 1976. (NASA CR-135020).

6. Cady, E. C. and Miyashiro, H.H., "Filling of Orbital Fluid Management Systems," MOC-G-7374, McDonnel1 Douglas Astronautics Co., Huntington Beach, CA, Aug. 1978. (NASA CR-159405).

7. Eberhardt, R.N., Gille, J.P., Bailey, W.J., and Berry, R.L., "Cryogenic Fluid Management Facility Concept Definition Study (CFMF)," MCR-83-536, Martin Marietta Denver Aerospace, Denver, C0, Dec. 1983. (NASA CR-174630).

8. Uhl, V.W. and Gray, J.B., eds., Mixing, Academic Press, New York, 1967, Volume 2 .

Table 1. - Summary of computer modeling parameters

(a) Tank Descriptions

\begin{tabular}{|c|}
\hline Prototype OTV Tank \\
\hline $\begin{array}{l}\text { Mass: } 5651 \mathrm{~km}(256 \mathrm{~kg}) \\
\text { Volume: } 1520 \mathrm{ft}^{3}\left(43 \mathrm{~m}^{3}\right) \\
M / V: 0.37 \mathrm{lbm} / \mathrm{ft}^{3}\left(6.0 \mathrm{~kg} / \mathrm{m}^{3}\right)\end{array}$ \\
\hline 0.25 Scaled Model Tank \\
\hline $\begin{array}{l}\text { Mass: } 70.9 \mathrm{lbm}(32.2 \mathrm{~kg}) \\
\text { Volume: } 23.6 \mathrm{ft}^{3}\left(0.75 \mathrm{~m}^{3}\right) \\
\text { M/V: } 3.0 \mathrm{bm} / \mathrm{ft}^{3}\left(42.9 \mathrm{~kg}^{3} / \mathrm{m}^{3}\right)\end{array}$ \\
\hline
\end{tabular}

(b) Operating Conditions

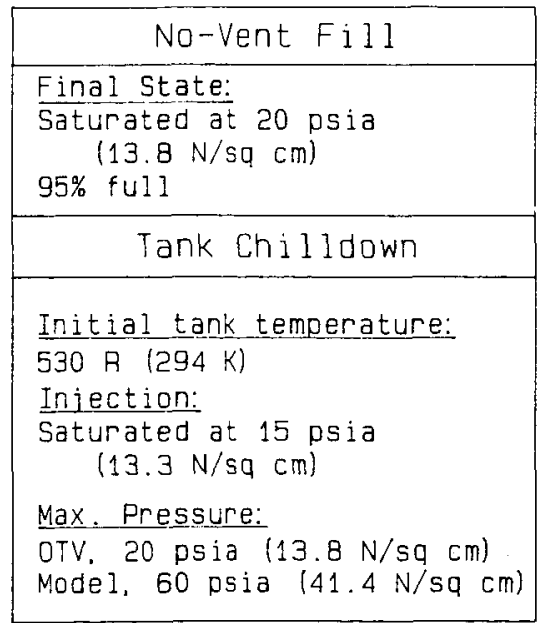

(c) Typical Modeling Results

\begin{tabular}{|c|}
\hline TARGET \\
\hline $\begin{array}{l}\text { Target temperatures } \\
\text { at } 5 \text { psi subcooling } \\
\text { OTV: } 393 \mathrm{~A}(218 \mathrm{~K}) \\
\text { Model: } 157 \mathrm{~A}(87 \mathrm{~K})\end{array}$ \\
\hline CRYOCHIL \\
\hline 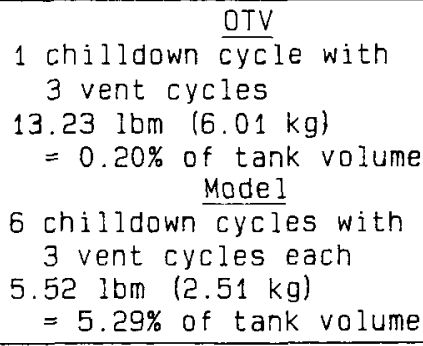 \\
\hline
\end{tabular}




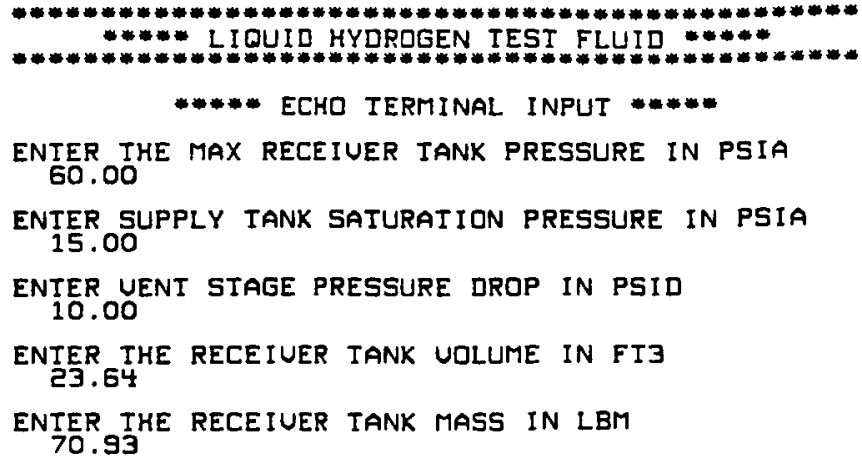

INITIAL IEMPERATURE FOR CYCLE 1 IS $530.000 R$

FINAL IANK TEMP BEFORE UENTING IS $482.697 R$

MASS INJECTED IN CYCLE 1 IS 0.576 LBM

TANK UENTED 7 TIME(S)

IANK TEMPERATURE AFTER UENIING IS $469.912 R$

INITIAL TEMPERATURE FOR CYCLE 2 IS 469.912 R

FINAL IANK IEMP BEFORE UENTING IS $421.032 R$

MASS INJECIED IN CYCLE 2 IS 0.661 LBM

IANK UENTED 7 TIME(S)

TANK TEMPERATURE AFIER UENTING IS $407.930 \mathrm{R}$

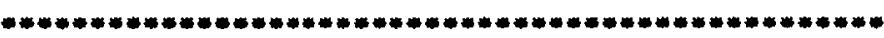

INITIAL TEMPERATURE FOR CYCLE 3 IS $407.930 \mathrm{R}$

FINAL TANK TEMP BEFORE UENTING IS $358.380 R$

MASS INJECTED IN CYCLE 3 IS 0.776 LBM

TANK UENTED 7 IIME(S)

IANK TEMPERATURE AFIER UENTING IS $344.892 R$

INITIAL IEMPERATURE FOR CYCLE 4 IS $344.892 R$

FINAL IANK TEMP BEFORE UENTING IS $294.079 R$

MASS INJECTED IN CYCLE 4 IS 0.946 LBM

IANK UENTED 7 TIME(S)

IANK IEMPERATURE AFTER UENTING IS $279.889 R$

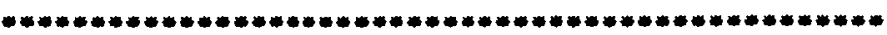

INIIIAL TEMPERATURE FOR CYCLE 5 IS $279.88 B$ R

FINAL IANK IEMP BEFORE UENTING IS $224.454 R$

MASS INJECIED IN CYCLE 5 IS 1.240 LBM

IANK UENTED 7 TIME(S)

TANK IEMPERATURE AFIER UENTING IS $208.141 \mathrm{R}$

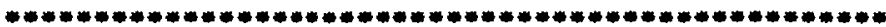

INITIAL IEMPERATURE FOR CYCLE 6 IS $208.141 R$

FINAL TANK TEMP BEFORE UENIING IS $167.706 \mathrm{R}$

MASS INJECTED IN CYCLE 6 IS 0.945 LBM

TANK UENTED 4 TIME(S)

TANK TEMPERATURE AFTER UENIING IS $157.000+1-0.500 R$

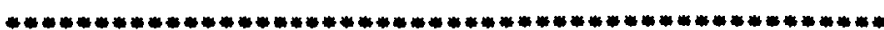

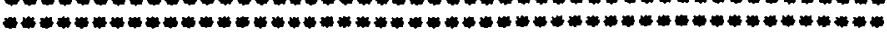

TDTAL MASS AFTER

6 CYCLE(S) IS
Conversion Factors

$1 \mathrm{lb}_{\mathrm{f}} / \mathrm{in}^{2}=0.689 \mathrm{~N} / \mathrm{cm}^{2}$

$1 \mathrm{ft}^{3}=0.0283 \mathrm{~m}^{3}$

$11 \mathrm{~b}_{\mathrm{m}}=0.454 \mathrm{~kg}$

$1^{{ }^{\circ}}{ }_{R}=0.556^{{ }^{\circ}} \mathrm{K}$ 


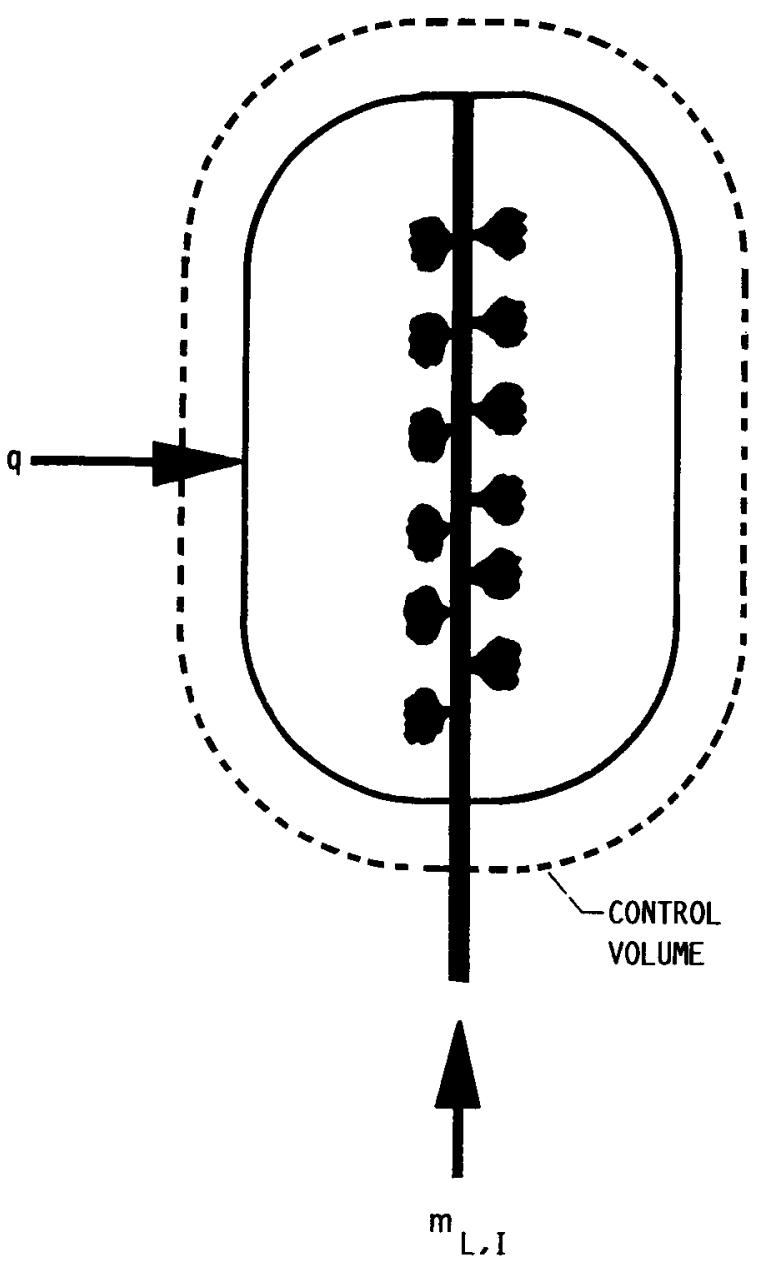

FIGURE 1. - SCHEMATIC REPRESENTATION OF AN OTV CRYOGENIC PROPELLANT TANK. 


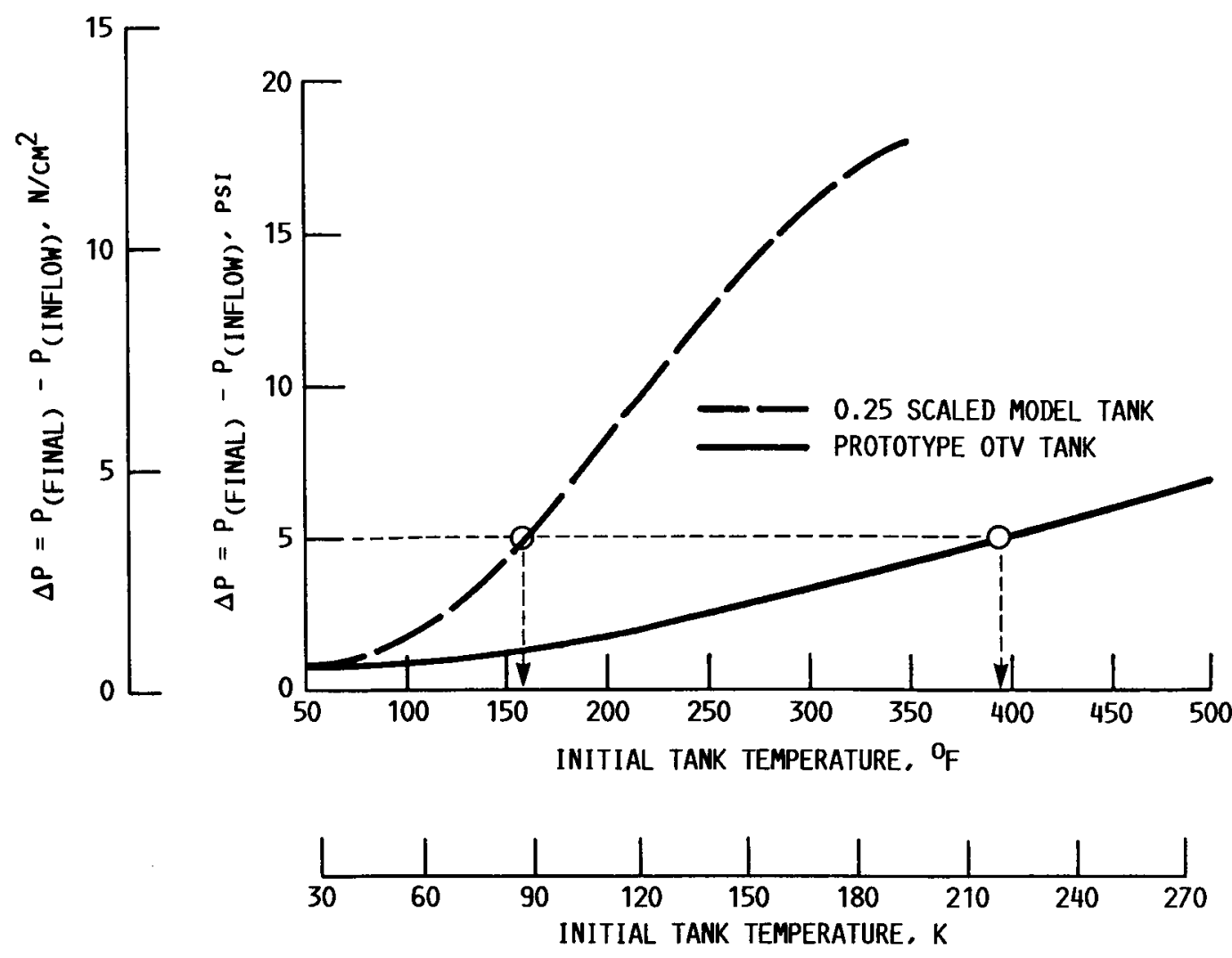

FIGURE 2. - REQUIRED LIQUID SUBCOOLING FOR A NO-VENT FILL - TARGET TEMPERATURE PREDICTION.
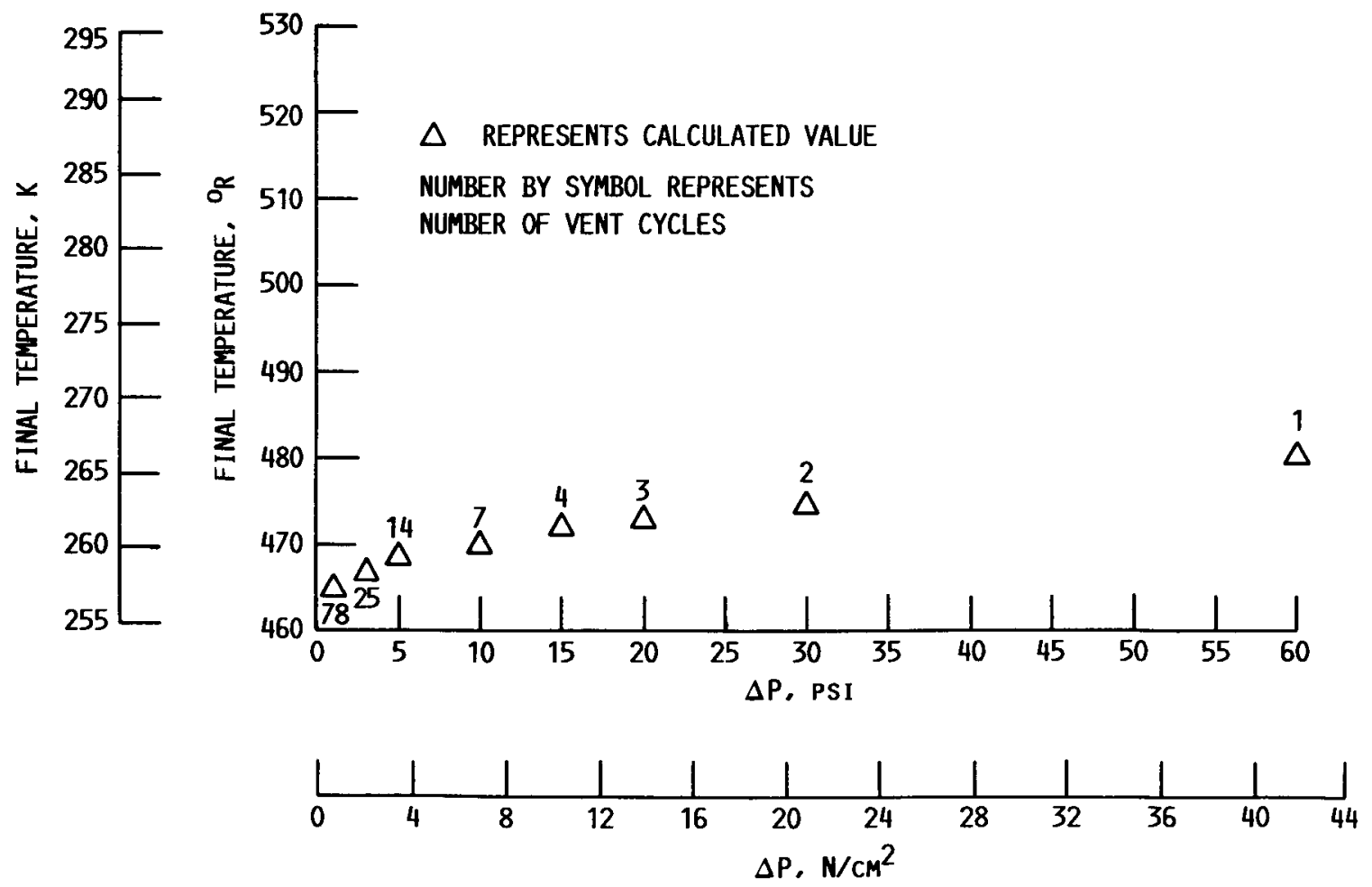

FIGURE 3. - EFFECT OF THE NUMBER OF VENT CYCLES ON THE COOLING CAPACITY OF ONE CHILLDOWN CYCLE. TANK SCALE $=0.25: P_{\text {MAX }}=60$ PSIA $\left(41.3 \mathrm{~N} / \mathrm{cm}^{2}\right) ; \mathrm{P}_{\text {SAT }}=30$ PSIA $\left(20.7 \mathrm{~N} / \mathrm{CM}^{2}\right) ; \mathrm{T}_{i}=5300_{\mathrm{R}}(294.4 \mathrm{~K})$. 

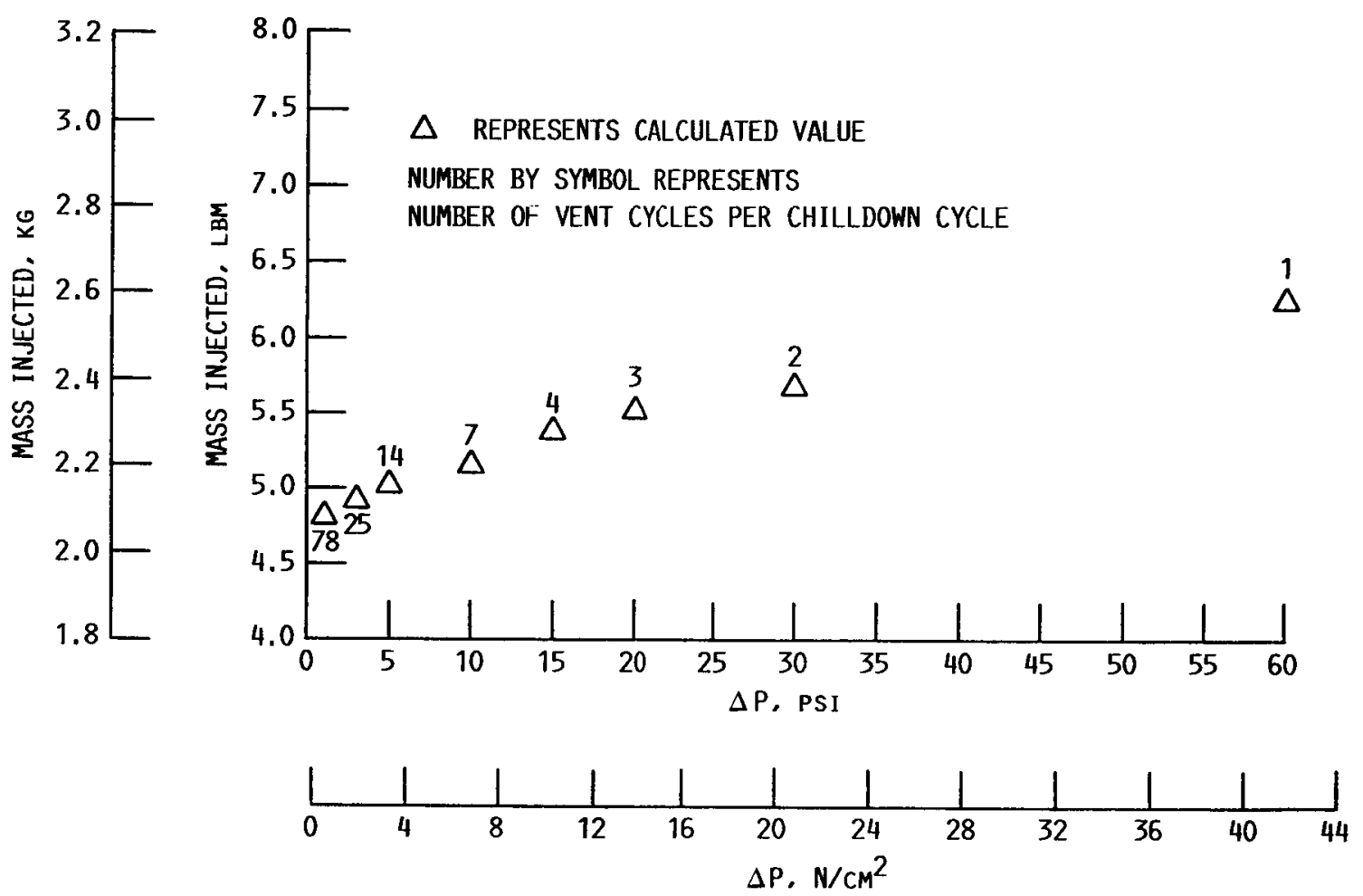

FIGURE 4. - EFFECT OF THE NUMBER OF VENT CYCLES ON THE MASS INJECTION REQUIREMENTS FOR A TANK CHILLDOWN. TANK SCALE $=0.25 ; \mathrm{P}_{\text {MAX }}=60 \mathrm{PSIA}\left(41.3 \mathrm{~N} / \mathrm{cm}^{2}\right) ; \mathrm{P}_{\text {SAT }}=30 \mathrm{PSIA}$ $\left(20.7 \mathrm{~N} / \mathrm{cm}^{2}\right) ; \mathrm{T}_{i}=5300_{\mathrm{R}}(294.4 \mathrm{~K}) ; \mathrm{T}_{\mathrm{f}} \stackrel{\mathrm{MAX}}{=} 140^{\circ} \mathrm{R}(77.8 \mathrm{~K})$. 


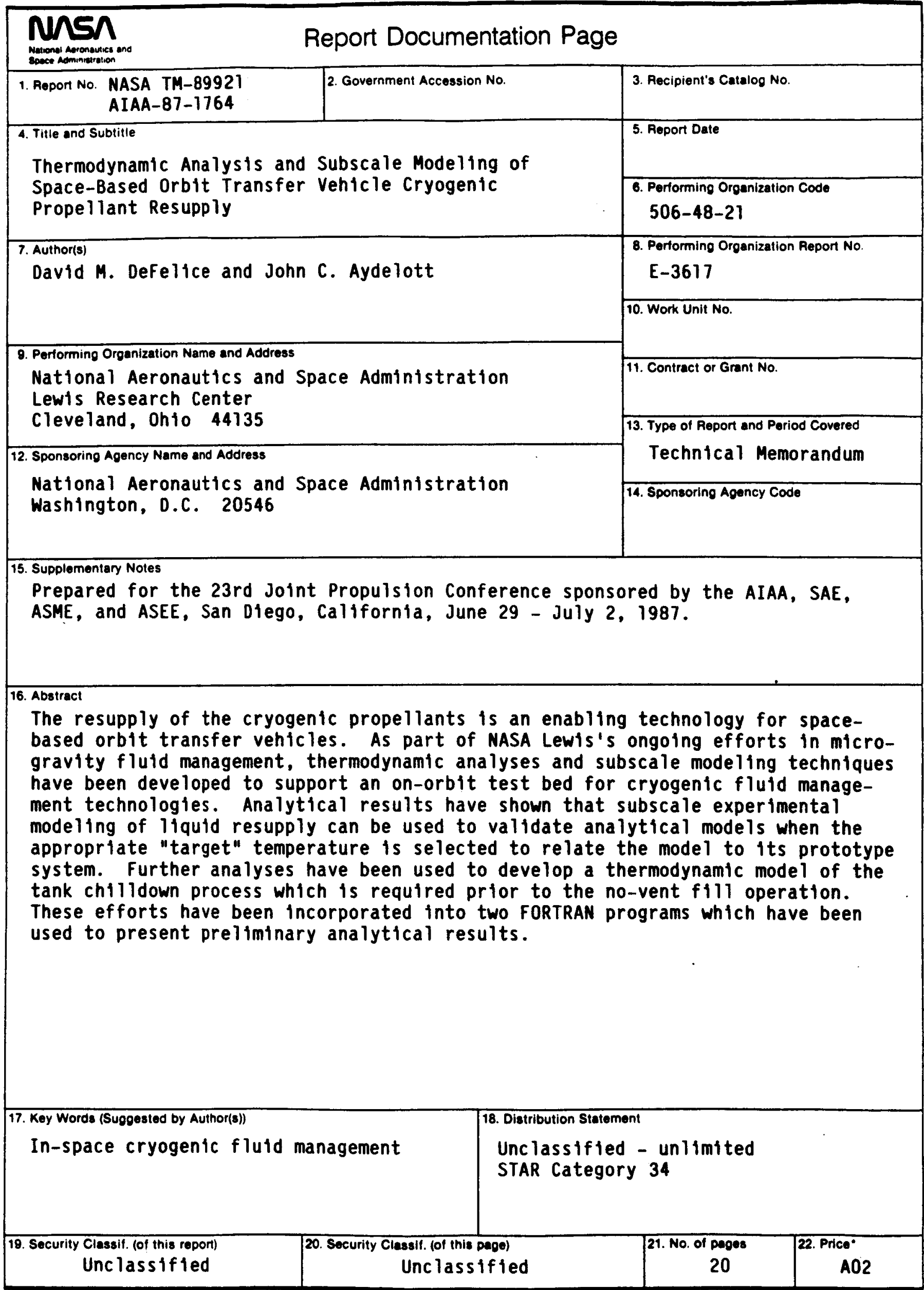

NASA FOAM 1626 OCT 86 "For sale by the National Technical Inlormation Service, Springfield, Virginia 22161 